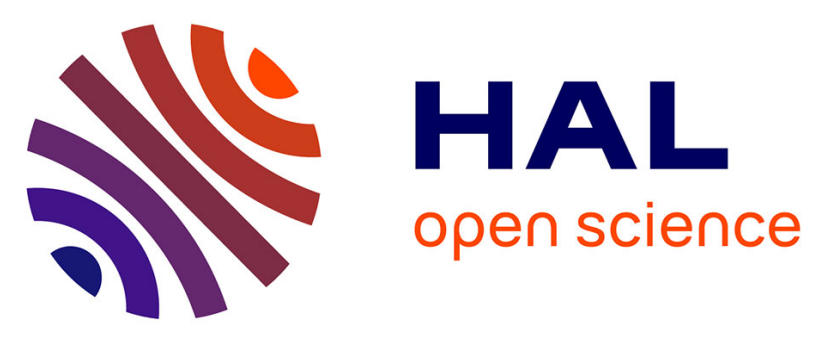

\title{
Risk factors for unsatisfactory colposcopy after large loop excision of the transformation zone: The results of a four-year multicenter prospective study
}

Julien Chevreau, Xavier Carcopino, Arthur Foulon, Lise Preaubert, Ségolène Lanta-Delmas, Fabrice Sergent, Jean Gondry

\section{To cite this version:}

Julien Chevreau, Xavier Carcopino, Arthur Foulon, Lise Preaubert, Ségolène Lanta-Delmas, et al.. Risk factors for unsatisfactory colposcopy after large loop excision of the transformation zone: The results of a four-year multicenter prospective study. European Journal of Obstetrics \& Gynecology and Reproductive Biology, 2019, 240, pp.156-160. 10.1016/j.ejogrb.2019.07.001 . hal-02468514

\section{HAL Id: hal-02468514 \\ https://hal.science/hal-02468514}

Submitted on 25 Oct 2021

HAL is a multi-disciplinary open access archive for the deposit and dissemination of scientific research documents, whether they are published or not. The documents may come from teaching and research institutions in France or abroad, or from public or private research centers.
L'archive ouverte pluridisciplinaire HAL, est destinée au dépôt et à la diffusion de documents scientifiques de niveau recherche, publiés ou non, émanant des établissements d'enseignement et de recherche français ou étrangers, des laboratoires publics ou privés.

\section{(ㅇ)(1) $\$$}

Distributed under a Creative Commons Attribution - NonCommerciall 4.0 International 
Full title: Risk factors for unsatisfactory colposcopy after large loop excision of the transformation zone: the results of a four-year multicenter prospective study.

Authors: Julien CHEVREAU (MD) ${ }^{1}$, Xavier CARCOPINO (MD-PhD) ${ }^{2}$, Arthur FOULON (MD) ${ }^{1}$, Lise PREAUBERT (MD)², Ségolène LANTA-DELMAS (MD)ํㅜ Fabrice SERGENT (MD-PhD) ${ }^{1}$, Jean GONDRY (MD-PhD) ${ }^{1}$

${ }^{1}$ Department of Obstetrics and Gynecology, University Hospital of Amiens, CHU AmiensPicardie, Avenue Laennec, Amiens Cedex 1, France

2 Department of Obstetrics and Gynecology, Hôpital Nord, Chemin des Bourrely, 13915, Marseille Cedex 20, France

Corresponding author: Julien CHEVREAU, Department of Obstetrics and Gynecology, University Hospital of Amiens, CHU Amiens-Picardie, 80054 Amiens cedex 1, France; +33(0) 322087400; chevreau.julien@chu-amiens.fr; ORCHID id: https://orcid.org/0000-0003-3933-9506.

Risk factors for unsatisfactory colposcopy after large loop excision of the transformation zone: the results of a four-year multicenter prospective study.

J. CHEVREAU, X. CARCOPINO, A. FOULON, L. PREAUBERT, S. LANTA-DELMAS, F. SERGENT, J. GONDRY 


\section{Abstract:}

Objectives: Not being able to completely examine the cervical squamocolummar junction (SCJ) in colposcopy after large loop excision of the transformation zone (LLETZ) is an important issue regarding surveillance, as high-grade cervical intra-epithelial neoplasia recurrence risk is high. This study was conducted in order to identify risk factors for post-LLETZ unsatisfactory colposcopy.

Methods: This prospective multicenter observational study was performed in nine French University hospitals, with inclusions running from December 2013 to December 2017. All patients scheduled for LLETZ were included and were divided into two groups after the two to four months post-procedure colposcopic examination: a satisfactory and an unsatisfactory postLLETZ colposcopy group.

Results: In total, 601 cases were analyzed and 71 post-LLETZ colposcopies (12\%) were described as unsatisfactory (including 19 cervical stenosis). In a univariate analysis, we only observed a statistically significant increase of the following parameters in the unsatisfactory post-LLETZ group in comparison with the satisfactory post-LLETZ group: parity $(2.11[ \pm 1.55]$ and $1.49[ \pm 1.24]$ respectively, $\mathrm{p}<.01)$, depth of the LLETZ specimen $(10.9 \mathrm{~mm}[ \pm 3.37]$ and $9.76[ \pm 3.79]$ respectively, $\mathrm{p}<.01)$, age $(45.9$ years $[ \pm 11.7]$ and $37.9[ \pm 9.42]$ respectively, $\mathrm{p}<.001)$ and an unsatisfactory pre-LLETZ colposcopy (43 satisfactory pre-LLETZ colposcopies [61\%] and 456 [86\%] respectively, $\mathrm{p}<.001)$. In a stepwise binary logistic regression analysis, only the two latter parameters were found to be independently associated with unsatisfactory post-LLETZ colposcopies

Conclusions: Surgeons should consider other therapeutic strategies when contemplating iterative diagnosis-LLETZ in older women with initially invisible SCJ, as an appropriate postLLETZ surveillance is at higher risk of being impossible to achieve.

Keys words: LLETZ; colposcopy; follow-up; risk; cervical squamocolummar junction; stenosis.

Introduction

Large loop excision of the transformation zone (LLETZ) is the reference treatment for highgrade cervical intra-epithelial neoplasia (HG CIN), and is widely used to prevent the development of invasive carcinoma [1]. Nevertheless, these women still present a higher post- 
LLETZ risk of invasion than the general population - multiplied by three or four depending on studies - and so adequate monitoring (colposcopy, in most cases) is therefore fundamental [2-5]. Complete visualization of the cervical squamocolummar junction (SCJ) is essential for qualifying post-LLETZ colposcopy as satisfactory [6].

The present study was thus conducted to identify risk factors for post-LLETZ unsatisfactory colposcopy. On this particular subject, current literature is limited, as most studies have solely focused on risk factors for cervical stenosis, frequently overlooking the position and visibility of the SCJ. The aim of this work was to allow surgeons to prevent modifiable risk factors for postLLETZ unsatisfactory colposcopy if they existed, and to adapt their practice when faced with non-modifiable risk factors if, they too, could be identified.

Materials and methods

\section{Patients}

This prospective multicenter observational study was performed in nine French University hospitals, with inclusions running from December 2013 to December 2017. Data was collated and analysed at Amiens-Picardie University hospital.

All patients scheduled for LLETZ were included. Given that the study's primary criterion for evaluation was an unsatisfactory post-LLETZ colposcopy, we excluded patients who required a hysterectomy after receipt of the final pathology results, patients who did not attend their postLLETZ appointment, and patients whose post-LLETZ colposcopy was not performed in the same institution as pre-LLETZ colposcopy. Written informed consents were obtained from all included patients, and the study received approval from the ethics committee of the French College of Obstetricians and Gynecologists, Paris, France in October 2013 (CEROG 2013-GYN-1001).

All included patients benefited from a pre-surgical colposcopy by a referral colposcopist. The following characteristics were systematically recorded: age, parity, and visualization of the SCJ. Two additional characteristics were also recorded when information was available: the use and type of any hormone treatments (either contraception or post-menopausal hormone replacement therapy), and smoking status.

\section{LLETZ procedures and specimen}


LLETZ-procedure was performed by a surgeon emanating from the pool of referral colposcopists, usually the same gynecologist that was consulted during the pre-surgical colposcopy. LLETZs were performed under local, regional or general anesthesia, after a final peroperative colposcopic examination, and using a semi-circular loop electrode (four possible diameters: 10, 15, 20, $25 \mathrm{~mm}$ ). The following characteristics were also recorded during the procedure: the need for further resection, use of destructive therapy (using ball diathermy), performance of electrocauterization, total dimensions of the excised specimen (depth and volume) before formaldehyde fixation.

LLETZ specimens were systematically set in a formaldehyde solution after having been oriented during the procedure. The results of the pathological results were recorded, along with the status of the exo- and endo-cervical margins excision margins. Margins were described as "negative" if both were free of dysplasia.

\section{Follow-up colposcopy}

All patients were scheduled for a follow-up colposcopy 2 to 4 months after LLETZ with her surgeon during which an evaluation of the SCJ was recorded. This period from conization to follow-up colposcopy was chosen in accordance with most frequently practiced managements in participating institutions. At that time, colposcopy was considered unsatisfactory if the SCJ was not fully visible (TZ3 according to the classification of the International Federation of Cervical Pathology and Colposcopy [6]) or/and a cervical stenosis was diagnosed. Cervical stenosis diagnosis was established during colposcopy at the discretion of each individual colposcopist. At this point, study participants were divided into two groups according to the study's primary endpoint: a satisfactory post-LLETZ colposcopy group, and an unsatisfactory post-LLETZ colposcopy group.

\section{Statistical analysis}

Data were expressed as the mean \pm standard deviation and $95 \%$ confidence intervals for continuous variables and as the number (percentage) for qualitative variables. Continuous variables were compared using the Mann-Whitney test, while categorical variables were compared using a $\chi 2$ test or Fisher's exact test (as appropriate). A binary logistic regression model was used to study factors found to be significantly associated with unsatisfactory postLLETZ colposcopy in a univariate analysis. Statistical analyses were performed on the website 
[https://www.pvalue.io], graphic interface of the R statistical software. The threshold for statistical significance was set to $\mathrm{p}<.05$ (two-sided).

Results

Out of the 641 initially recruited patients, 40 were excluded due to either necessity for hysterectomy after final pathologic results or unavailable post-LLETZ colposcopy (patient did not attend to her post-LLETZ appointment, or post-LLETZ colposcopy was not performed in our institution). In total, 601 cases were analyzed. Regarding the primary criterion for evaluation, $530(88 \%)$ post-LLETZ colposcopies were described as satisfactory and $71(12 \%)$ as unsatisfactory. The latter group comprised 52 TZ3 classified SCJ and 19 cervical stenosis.

In a univariate analysis, there were no significant intergroup differences according to electrode diameter, necessity of further resection, use of destructive therapy, performance of electrocauterization, volume of LLETZ specimen, final pathological results, and status of margins. On the other hand, we observed a statistically significant increase of unsatisfactory post-LLETZ colposcopies with the increase of the following parameters: age, parity, and depth of the LLETZ specimen. An unsatisfactory pre-LLETZ colposcopy was also statistically associated with an unsatisfactory post-LLETZ colposcopy (table 1).

When data was available (444 cases), we did not observe any intergroup difference regarding type of hormonal treatment. Indeed the satisfactory and unsatisfactory post-LLETZ groups respectively comprised 90 (23\%) and 5 (10\%) patients using estrogen (p=.07), 63 (16\%) and 13 $(27 \%)$ patients using oral progestatives $(\mathrm{p}=.1), 62(16 \%)$ and $4(8 \%)$ patients bearing a levonorgestrel intra-uterin device ( $\mathrm{p}=.23)$, and 180 (46\%) and 27 (55\%) patients without any hormonal treatment ( $p=.26)$. Likewise, when data was recorded (444 patients), we did not observe any intergroup differences with regard to smoking status: the satisfactory and unsatisfactory post-LLETZ groups respectively comprised 177 (45\%) and 19 (39\%) active smokers $(\mathrm{p}=.45)$.

In a stepwise binary logistic regression analysis, age at LLETZ and an unsatisfactory pre-LLETZ colposcopy were found to be independently associated with unsatisfactory post-LLETZ colposcopies (table 2). 


\section{Comment}

Adequate visualization of the SCJ is fundamental in order to rapidly detect HG CIN. This is especially the case after a LLETZ procedure, since recurrence is frequent and these women are three to four times as likely as women in the general population to develop cervical cancer after LLETZ - even when the surgical margins are clear [7,8]. Cervical stenosis is one cause for unsatisfactory post-LLETZ colposcopy (because the stenosis prevents adequate evaluation of the $\mathrm{SCJ}$ ), and has been widely studied over the past, in contrast with incomplete evaluation of the SCJ, an equally important but far less studied factor for unrecognized HG CIN recurrence [9-11]. In the present study, an initially incomplete visualization of the SCJ prior to the excisional procedure seemed to constitute a first risk factor for unsatisfactory post-LLETZ colposcopy. This parameter had to this date but rarely been evaluated but seems nevertheless important to consider. Indeed, a persistent abnormal cytology associated with an incomplete visualization of the SCJ is in certain cases an indication for "diagnosis-LLETZ" [12]. Colposcopists contemplating such a procedure should therefore bear in mind that the same situation might present itself after LLETZ in case of abnormal cytology as unsatisfactory colposcopy will have an important risk of remaining unsatisfactory after excision. In our study, age was also identified as an independent risk factor for unsatisfactory colposcopy after LLETZ. This is consistent with current literature, and seems to be independent of menopausal status $[13,14]$. Mean patient age in the unsatisfactory post-LLETZ colposcopy being relatively high in comparison with women presenting a complete vision of the SCJ in our cohort (45.9 vs 37.9 years), it could be argued that in case of recurring cytological abnormalities for women presenting a recurrent TZ3 after an initial LLETZ procedure, iterative "diagnosis" excision might not be adapted, and hysterectomy could be discussed. Furthermore, the results from the ICORAD study by Carcopino et al. comparing satisfactory and unsatisfactory post-LLETZ colposcopies showed that a history of previous excisional cervical therapy was in itself a risk factor for inadequate post-treatment colposcopy [adjusted odds ratio $(\mathrm{aOR})=4.29,95 \% \mathrm{CI}=1.12-16.37, \mathrm{p}=.033$ ] [15] . This further emphasizes the necessity of setting up an alternative strategy to a series of "diagnostic" LLETZ procedures in case of recurring Pap smear abnormalities for older women presenting a recurrent TZ3 after the initial conisation. Before contemplating hysterectomy, however, certain precautions should be taken. First, a careful vaginal inspection should have been performed in order not to neglect vaginal recurrences, which, though rare, are often more difficult to diagnose. Second, as shown by Arbyn et al. in an extensive review comprising 97 studies and 44446 
women treated for cervical precancer, high-risk HPV testing seems an obligatory step before indicating radical surgery [16]. Indeed, authors reported a pooled sensitivity and specificity to predict residual or recurrent HG CIN of 91\% (82.3-95.5) and 83.8\% (77.7-88.7), respectively, for high-risk HPV testing, which predicted treatment failure more accurately than margin status. Given their wide availability, these situations could benefit from high-risk HPV tests, and only in case of a positive testing could radical surgery be discussed.

As mentioned above, a high-quality post-LLETZ examination is essential for a prompt diagnosis of recurrence. The identification of factors susceptible of being modified to obtain a visible postexcision SCJ is therefore a necessity, if they exist. Unfortunately, none was identified in the present study, regardless of whether one considers the surgical procedure per se (the diameter of the semicircular loop electrodes, the dimensions of the excised specimen, or the use of adjuvant therapies) or patient-related parameters (tobacco use, hormone replacement therapy or the use of hormonal contraception). In contrast to the present findings, some researchers have reported an influence of specimen dimensions where an increased excised depth was associated with higher rates of stenosis [17-19]. However, in these studies, depth cutoffs were set much higher than today's standards (as high as $25 \mathrm{~mm}$ ) and excision volumes were never evaluated. Furthermore, cervical excisions were performed using a variety of methods, including dated technics such as cold knife conization. An interesting and promising adaptation of the LLETZ technique has been evaluated by Carcopino et al. in a prospective work on 157 postLLETZ colposcopies. Authors found that the direct use of colposcopy during the excision procedure was significantly associated with a decrease in the risk of post-LLETZ inadequate colposcopy $(\mathrm{aOR}=0.19,95 \% \mathrm{CI}=0.04-0.80, \mathrm{p}=.024)$ [15]. Although colposcopic-guided LLETZ is doubtless subject to a learning curve, this method should nevertheless be considered by surgeons in general and by younger gynecologists in training in particular, especially as no compromise was reported regarding margin status [20]. This modification of practice seems unavoidable, as, for instance, the use of colposcopy during conization was recommended in the latest report of the French National Cancer Institute on cervical lesion treatment in 2016 [21]. The influence of adjuvant treatments (such as electrocauterization, peripheral ball electrode diathermic destruction, and additional resections) on cervical scarring has not been clearly established. Regarding influence on HG CIN recurrence themselves, these therapies have not even demonstrated a major positive impact, as shown in a recent prospective study on risk factors for these recurrences, comprising 204 post-LLETZ follow-ups. Authors reported that additional peripheral ablative therapy had no influence with respectively in the recurrent and non-recurrent groups, use of additional ablative therapy in 2 (25\%) and $43(21.9 \%)$ of cases, $p=$ .734) [22]. Although theses therapies have yet to prove their therapeutic efficiency, and further 
prospective studies are needed to this effect, our results showed that they at least had no retraction effect into the endocervical canal of the SCJ, which is concordant with previous studies on the subject [15]. However, before concluding to a complete harmlessness of these adjuvant therapies, their obstetrical consequences should be evaluated.

The question of the influence of certain exogenous agents such as tobacco and hormones on cervical tissue has been addressed by Carcopino et al. in a retrospective study conducted on 1248 patients where the aim was determining whether the time of the menstrual cycle would improve the likelihood of visualizing the entire SCJ at colposcopy [14]. Although an external estrogen input was not tested, the results of this study showed no better chance of visualization of the SCJ at colposcopy during the follicular phase of the menstrual cycle, thus contradicting common beliefs that SCJ shifts outwards during the menstrual cycle under estrogen influence. These findings are apparently transposable, in view of our results, to exogenous estrogen input. Likewise, exogenous input of progesterone, whether locally or parenterally, had no influence on the visibility of the SCJ in our study, thus ruling out any theory of SCJ endocervical retraction under this class of hormonal adjunction. These findings confirmed results from a previous retrospective study on post-LLETZ stenosis where it was reported that the use of "oral contraceptives" had non influence: 2/43 (4.6\%) oral contraceptive users and 8/121 (6.6\%) nonusers presented stenosis ( $p$.99) [23]. It should be noted, however, that these results on influence of hormones on cervical tissue should be, in our study, interpreted with caution. Indeed, even though the p-values failed to pass the 0.05 threshold for significance, they were very close. The fact that sample size for each hormonal class was relatively small may have led to false negative findings, especially since the direction of the intergroup differences - positive influence of estrogen and negative influence of oral progestatives - was the same as what is commonly believed regarding shifting of the SCJ (outwards under estrogen influence, inwards under progestative influence). Regarding the effect of tobacco on cervical tissue, the authors of the same study described a negative influence of smoking on colposcopic visualization of the SCJ $(\mathrm{aOR}=0.53,95 \% \mathrm{CI}=0.40-0.71, \mathrm{p}<.001)$, which we did not report. According to the authors themselves, these findings were rather unexpected and remained unexplained. Hence, we naturally recommend the cessation of tobacco use to decrease risk of HG CIN recurrence and squamous cell carcinoma development as it has clearly been assessed as such a risk factor, but not in order to obtain satisfactory post-LLETZ colposcopy [24].

Final pathological results and margin status are key factors in HG CIN recurrences or invasive carcinoma development [25]. The influence of these parameters on post-LLETZ colposcopy is, 
on the other hand, less clear. In Suh-Burgmann et al.'s retrospective study of risk factors for cervical stenosis, there was only a non-significant trend towards an influence of severe dysplasia on the final pathology results: $8 / 80(10 \%)$ patients presenting severe dysplasia and only $2 / 84$ $(2.4 \%)$ presenting less severe dysplasia on final pathological examination presented stenosis, $\mathrm{p}$ $=.053$ [23]. In their prospective study on inadequate post-LLETZ colposcopy, Carcopino et al. reported no influence of final pathological results, regardless of whether final endpoint was defined as a TZ3 SCJ or a cervical stenosis [15]. In the same study, the achievement of negative margins, on the other hand, seemed to significantly reduce risk of post-LLETZ TZ3 without influencing risk of stenosis. The authors acknowledged that further inclusions were needed, but an explanation could be that not achieving clear endocervical margins, and therefore not fully excising the SCJ, the healing process might result in the burying of the junction deep in the cervical canal. The extension of the inclusions in our study gave us a clearer idea of the influence of margins and the final pathology results - neither of which had a statistically significant relationship with the quality of the post-LLETZ colposcopy. These are important, reassuring results: positive margins and severe dysplasia in the final pathology assessment are well-known risk factors for the recurrence of HG CIN and the development of invasive carcinoma; had these factors been associated with a higher rate of unsatisfactory post-LLETZ colposcopies, the resulting surveillance (which should be particularly meticulous in such cases) would have been more hazardous. Fortunately, this was not the case, implying that positive margins and severe dysplasia on final pathological examination are not at risk of inducing higher rates of unseen recurrences or invasions, at least not due to a burying of the SCJ in the cervical canal.

Regarding this work, it could be argued that the subjectivity of the colposcopic examination constituted a bias when classifying SCJ. The fact that most pre- and post-LLETZ colposcopies were performed by the same practitioner (and surgeon) nevertheless limited the statistical influence of the interpretability of colposcopy. Another bias that should be considered when interpreting our results is the fact that the primary endpoint was evaluated only two to four months after LLETZ. On one hand, it could be argued that an early examination could lead to a hindered colposcopy due to incomplete cervical cicatrisation, but incomplete scaring was never reported in our study. On the other hand, early follow-up could also be responsible for an under evaluated ratio of unsatisfactory post-LLETZ colposcopies, with certain stenosis appearing only later. Nevertheless, proportions of post-LLETZ TZ3 and stenosis in our study were similar to what was reported by most authors, indicating that most TZ3 and stenosis could already be present at this two to four months period [23;26]. Regarding previous studies evaluating postLLETZ complications, time of evaluation was extremely inconstant, ranging from two or three 
months after surgery, to 37 months in some cases $[10,11 ; 15 ; 19]$. This two to four months postLLETZ evaluation period was therefore consistent with previous studies, as well as in adequacy with most of the participating institutions' protocols at the time of study. Finally, as stated before, the small number of participants in our study limited the interpretation of results when certain variables were concerned, as it was the case with hormonal use when separate categories needed to be isolated before analysis.

Conclusions of this study imply important clinical repercussions: although we did not identify modifiable factors potentially enabling an easier post-LLETZ surveillance, surgeons should however be aware that older women and initially invisible SCJ were identified as independent risk factors for unsatisfactory post-LLETZ colposcopy. This is critical when considering iterative "diagnosis-LLETZ" for these patients, as subsequent post-surgery surveillance is likely to be impossible to achieve. In those cases, other therapeutic strategies should be considered, such as high-risk HPV testing and even, as a last resort, hysterectomy in some situations.

Authors presented no conflict of interest with the present study.

\section{References}

[1] Martin-Hirsch PP, Paraskevaidis E, Bryant A, Dickinson HO, Keep SL. Surgery for cervical intraepithelial neoplasia. Cochrane Database Syst Rev 2010; 6: CD001318.

[2] Strander B, Andersson-Ellström A, Milsom I, et al. Long term risk of invasive cancer after treatment for cervical intraepithelial neoplasia grade 3: population based cohort study. BMJ 2007;335:1077. 
[3] Soutter WP, de Barros Lopes A, Fletcher A, et al. Invasive cervical cancer after conservative therapy for cervical intraepithelial neoplasia. Lancet 1997;349:978-80.

[4] Verguts J, Bronselaer B, Donders G, et al. Prediction of recurrence after treatment for highgrade cervical intraepithelial neoplasia: the role of human papillomavirus testing and age at conisation. BJOG 2006; 113:1303-7.

[5] Paraskevaidis E, Arbyn M, Sotiriadis A, et al. The role of HPV DNA testing in the follow-up period after treatment for CIN: a systematic review of the literature. Cancer Treat Rev 2004;30:205-11.

[6] Bornstein J, Bentley J, Bösze P, et al. 2011 colposcopic terminology of the International Federation for Cervical Pathology and Colposcopy. Obstet Gynecol 2012; 120:166-72.

[7] Rebolj M, Helmerhorst T, Habbema D, et al. Risk of cervical cancer after completed posttreatment follow-up of cervical intraepithelial neoplasia: population based cohort study. BMJ 2012;345:e6855

[8] Melnikow J, McGahan C, Sawaya GF, et al. Cervical intraepithelial neoplasia outcomes after treatment: long-term follow-up from the British Columbia Cohort Study. J Natl Cancer Inst 2009;101:721-8.

[9] Penna C, Fambrini M, Fallani MG, et al. Laser CO2 conization in postmenopausal age: risk of cervical stenosis and unsatisfactory follow-up. Gynecol Oncol 2005;96:771-5.

[10] Houlard S, Perrotin F, Fourquet F, et al. Risk factors for cervical stenosis after laser cone biopsy. Eur J Obstet Gynecol Reprod Biol 2002;104:144-7.

[11] Monteiro AC, Russomano FB, Camargo MJ, Silva KS, Veiga FR, Oliveira RG. Cervical stenosis following electrosurgical conization. Sao Paulo Med J 2008;126:209-14.

[12] Institut National du Cancer, ed. Conduite à tenir devant une femme ayant une cytologie cervico-utérine anormale. Boulogne-Billancourt : 2016.

[13] Wetrich DW. An analysis of the factors involved in the colposcopic evaluation of 2194 patients with abnormal Papanicolaou smears. Am J Obstet Gynecol 1986;154:1339-49.

[14] Carcopino X, Akkawi R, Conroy R, et al. Specific timing for colposcopy: is it worthwhile? Obstet Gynecol 2008;111:373-7. 
[15] Carcopino X, Mancini J, Gondry J, et al. Risk Factors of Inadequate Colposcopy After Large Loop Excision of the Transformation Zone: A Prospective Cohort Study. J Low Genit Tract Dis 2018;22:31-7.

[16] Arbyn M, Redman CW, Verdoodt F, Kyrgiou M, Tzafetas M, Ghaem-Maghami S, et al. Incomplete excision of cervical precancer as a predictor of treatment failure: a systematic review and meta-analysis. Lancet Oncol 2017; 18: 1665-79.

[17] Mazouni C, Porcu G, Haddad O, Dallès JP, Taranger-Charpin C, Piana L, et al. Conservative treatment of cervical intra epithelial neoplasia using a cold knife section technique. Eur J Obstet Gynecol Reprod Biol 2005;121 :86-93.

[18] Hammond R, Edmonds D. Does treatment for cervical intraepithelial neoplasia affect fertility and pregnancy? BMJ 1990;301:1344-5.

[19] Baldauf JJ, Dreyfus M, Ritter J, Meyer P, Philippe E. Risk of cervical stenosis after large loop excision or laser conization. Obstet Gynecol 1996;88:933-8.

[20] Preaubert L, Gondry J, Mancini J, et al. Benefits of direct colposcopic vision for optimal LLETZ procedure: a prospective multicenter study. J Low Genit Tract Dis 2016; 20: 15-21.

[21] Institut National du Cancer (INCa). Conduite à tenir devant une femme ayant une cytologie cervico-utérine anormale - Thésaurus, Collection recommandations et référentiels. 2016.182 p.

[22] Demarquet E, Mancini J, Preaubert L, et al. Risk factors of post-LLETZ recurrent high-grade cervical intraepithelial lesion: a prospective cohort study. J Low Genit Tract Dis 2018 Aug 6. doi: 10.1097/LGT.0000000000000423. [Epub ahead of print]

[23] Suh-Burgmann EJ, Whall-Strojwas D, Chang Y, Hundley D, Goodman A. Risk factors for cervical stenosis after loop electrocautery excision procedure. Obstet Gynecol 2000;96:657-60.

[24] International Collaboration of Epidemiological Studies of Cervical Cancer. Comparison of risk factors for invasive squamous cell carcinoma and adenocarcinoma of the cervix: collaborative reanalysis of individual data on 8,097 women with squamous cell carcinoma and 1,374 women with adenocarcinoma from 12 epidemiological studies. Int J Cancer 2007;120: 885-91.

[25] Ghaem-Maghami S, De-Silva D, Tipples M, et al. Determinants of success in treating cervical intraepithelial neoplasia. BJOG 2011;118:679-84. 
[26] Thompson V, Marin R. Is colposcopy necessary at twelve months after large loop excision of the transformation zone? A clinical audit. Aust N Z J Obstet Gynaecol 2013; 53:571-3.

Table Legends

Table 1: Patients' characteristics according to the post-LLETZ colposcopy aspect

Table 2: Factors associated with unsatisfactory post-LLETZ colposcopy (Binary logistic regression model) 
Table 1: Patients' characteristics according to the post-LLETZ colposcopy aspect

\begin{tabular}{|c|c|c|c|}
\hline & $\begin{array}{l}\text { Satisfactory post- } \\
\text { LLETZ colposcopy }\end{array}$ & $\begin{array}{l}\text { Unsatisfactory post- } \\
\text { LLETZ colposcopy }\end{array}$ & $p$-value \\
\hline $\mathrm{n}$ & 530 & 71 & \\
\hline $\begin{array}{l}\text { Age, mean }(y) \pm S D \text { and } \\
95 \% \mathrm{Cl}\end{array}$ & $\begin{array}{l}37.9( \pm 9.42)[37.1 ; \\
38.7]\end{array}$ & $\begin{array}{l}45.9( \pm 11.7)[43.2 ; \\
48.6]\end{array}$ & $<.001^{* * *}$ \\
\hline $\begin{array}{l}\text { Parity, mean } \pm \text { SD and } \\
95 \% \mathrm{Cl}\end{array}$ & $\begin{array}{l}1.49( \pm 1.24)[1.38 ; \\
1.6]\end{array}$ & $\begin{array}{l}2.11( \pm 1.55)[1.75 ; \\
2.47]\end{array}$ & $<.01 * *$ \\
\hline Smoking status, n (\%) & $177(45 \%)$ & $19(39 \%)$ & .45 \\
\hline $\begin{array}{ll}\text { Hormonal use, } \mathrm{n}(\%): \\
\text { - } & \text { Estrogen } \\
\text { - } & \text { Oral progestatives } \\
\text { - } & \text { Levonorgestrel } \\
& \text { intra-uterin device } \\
\text { - } & \text { none }\end{array}$ & $\begin{array}{l}90(23 \%) \\
63(16 \%) \\
62(16 \%) \\
180(46 \%)\end{array}$ & $\begin{array}{l}5(10 \%) \\
13(27 \%) \\
4(8 \%) \\
27(55 \%)\end{array}$ & $\begin{array}{l}.07 \\
.1 \\
.23 \\
\\
.26\end{array}$ \\
\hline $\begin{array}{l}\text { Initial visualization of the } \\
\text { SCJ, } n(\%)\end{array}$ & 456 (86\%) & $43(61 \%)$ & $<.001^{* * *}$ \\
\hline $\begin{array}{l}\text { Loop diameter, mean } \\
(\mathrm{mm}) \pm \mathrm{SD} \text { and } 95 \% \mathrm{Cl}\end{array}$ & $\begin{array}{l}18.0( \pm 4.12)[17.6 ; \\
18.4]\end{array}$ & $\begin{array}{l}17.3( \pm 4.29)[16.3 ; \\
18.3]\end{array}$ & .14 \\
\hline $\begin{array}{l}\text { Excised specimen total } \\
\text { depth, mean }(\mathrm{mm}) \pm \mathrm{SD} \\
\text { and } 95 \% \mathrm{Cl}\end{array}$ & $\begin{array}{l}9.76( \pm 3.79)[9.44 ; \\
10.1]\end{array}$ & $\begin{array}{l}10.9( \pm 3.37)[10.1 ; \\
11.7]\end{array}$ & $<.01 * *$ \\
\hline $\begin{array}{l}\text { Excised specimen total } \\
\text { volume, mean }(\mathrm{mL}) \pm \mathrm{SD} \\
\text { and } 95 \% \mathrm{Cl}\end{array}$ & $\begin{array}{l}2.43( \pm 1.38)[2.31 ; \\
2.55]\end{array}$ & $\begin{array}{l}2.58( \pm 1.32)[2.27 \\
2.89]\end{array}$ & .20 \\
\hline Further resection, $\mathrm{n}(\%)$ & $83(16 \%)$ & $16(23 \%)$ & .19 \\
\hline $\begin{array}{l}\text { Addition concomitant } \\
\text { destructive therapy, } \mathrm{n}(\%)\end{array}$ & $189(36 \%)$ & $24(34 \%)$ & .86 \\
\hline Electrocauterization, n (\%) & $475(90 \%)$ & $67(94.4 \%)$ & .29 \\
\hline 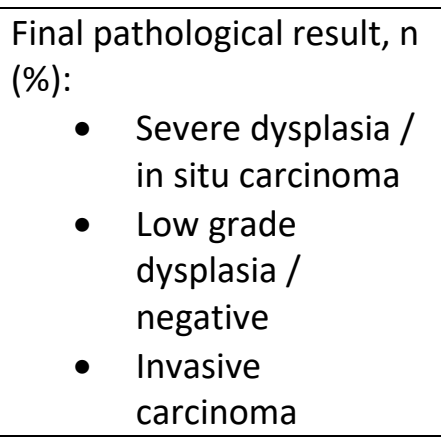 & $\begin{array}{l}422(80 \%) \\
105(20 \%) \\
3(<1 \%)\end{array}$ & $\begin{array}{l}61(86 \%) \\
10(14 \%) \\
0\end{array}$ & .3 \\
\hline Negative margins, $\mathrm{n}(\%)$ & $438(83 \%)$ & $52(73 \%)$ & .06 \\
\hline
\end{tabular}

$\mathrm{Cl}=$ confidence interval; LLETZ = Large loop excision of the transformation zone; $\mathrm{SCJ}=$ squamocolummar junction; SD = standard deviation; * marks statistically significant results 
Table 2: Factors associated with unsatisfactory post-LLETZ colposcopy (Binary logistic regression model)

\begin{tabular}{|l|l|l|}
\hline & aOR $(95 \% \mathrm{Cl})$ & $\mathrm{p}$-value \\
\hline Age & $0.951[0.926 ; 0.977]$ & $<.001^{* * *}$ \\
\hline Parity & $0.823[0.677 ; 1.00]$ & .43 \\
\hline Excised specimen total depth & $0.973[0.908 ; 1.04]$ & .052 \\
\hline Initial visualization of the SCJ & $0.516[0.278 ; 0.958]$ & $.036^{*}$ \\
\hline
\end{tabular}

aOR = adjusted odds ratio; $\mathrm{Cl}$ = confidence interval; LLETZ = Large loop excision of the transformation zone; $\mathrm{SCJ}=$ squamocolummar junction; ${ }^{*}$ marks statistically significant results 